\title{
2 Aerosol Characteristics in the Three Poles of the Earth 3 Observed by CALIPSO
}

4

5 Yikun Yang ${ }^{1,2}$, Chuanfeng Zhao ${ }^{1,2}$, Quan Wang ${ }^{3}$, Zhiyuan Cong ${ }^{4}$, Xingchun Yang ${ }^{1,2}$, 6 Hao Fan ${ }^{1,2}$

7

8

Table S1. Detail information about the location and release height of HYSPLIT back trajectory simulations at ten selected sites in the Arctic (N1-N4), Antarctic (S1-S4), and TP (TP1 and TP2).

\begin{tabular}{ccccc}
\hline Abb. & Longitude $\left(^{\circ}\right)$ & Latitude $\left(^{\circ}\right)$ & Altitude $(\mathrm{m})$ & Location \\
\hline N1 & -43.0 & 75.0 & 500 & Greenland \\
N2 & 47.0 & 80.0 & 500 & Franz Josef Land \\
N3 & 136.0 & 76.0 & 500 & New Siberian Islands \\
N4 & -122.0 & 73.0 & 500 & Victoria Island \\
S1 & -70.0 & -72.0 & 500 & Antarctic Peninsula \\
S2 & -160.0 & -75.0 & 500 & Ross Sea \\
S3 & 30.0 & -70.0 & 500 & Dronning Maud Land \\
S4 & 122.0 & -68.0 & 500 & Wilkes Land \\
TP1 & 89.0 & 37.0 & 500 & The Northern edge of TP \\
TP2 & 84.0 & 30.0 & 500 & The Southern edge of TP \\
\hline
\end{tabular}

11 Noted that altitude represents the source of aerosol at this height is simulated in this study, but it is 12 not the actual altitude of the site. 